\title{
Untimely Reviews
}

(C) Springer Science+Business Media Dordrecht 2012

Some philosophical works are considered "classics", and are regarded as an everlasting source of inspiration for scholars and as full of fresh ideas and timely insights. But such ambitious claims should be put to the test of critical assessment, rather than tacitly agreed to: Does a certain classic truly fit into the current philosophical debate as a significant and relevant contribution, or does it rather show the signs of age, having been partially or even totally outpaced by more recent and comprehensive works? Could it live up to its fame, if it were to appear here and now on the philosophical scene?

Here historical considerations can be no excuse: It is true (and obvious) that contemporary contributions have been influenced and even inspired by the same classic work which is being judged against them, but we are discussing philosophy as a dialogical, provocative, and challenging activity, one that does not grant badges of honor due to past merits. Hence we want to verify whether, and to what extent, a certain milestone of philosophy can still be a lively voice in the contemporary debate, and to what extent, on the other hand, it is fatally outdated.

Topoi's Untimely Reviews are based on this premise, and attempt a serious experiment of counterfactual analysis:
We take a classic of philosophy and ask an outstanding scholar in the same field to review it as if it had just been published. This implies that the classical work must be contrasted with both past and current literature and must be framed in the wider cultural context of the present day. The result is a litmus test for the work itself: Failure in accounting for relevant issues raised by contemporary literature reveals that, in those respects, our classic has indeed been outpaced by later works. On the other hand, any success in capturing core topics of current discussion, or even anticipating and clarifying issues not yet well brought into focus by contemporary scholars, is the strongest proof of the liveliness of the work, no matter how long ago it was written.

Such musings are utterly pointless for philology or the history of ideas, but they are highly meaningful if we want to shed new light on the topics addressed by those authors. It is in this spirit that an untimely review is written and should be read: as the best way to truly honor a philosophical work, by constantly facing it with new, unpredictable, and demanding challenges.

\section{The Editor}

